CLINICAL STUDY

\title{
Obesity-related cardiovascular risk factors after weight loss: a clinical trial comparing gastric bypass surgery and intensive lifestyle intervention
}

\author{
D Hofs $\varpi^{1}$, N Nordstrand ${ }^{1}$, L K Johnson ${ }^{1}$, T I Karlsen ${ }^{1,2}$, H Hager $^{3}$, T Jenssen ${ }^{4,5}$, J Bollerslev ${ }^{6,7}$, K Godang ${ }^{6}$, \\ $\mathrm{R} \mathrm{Sandbu}^{1}$, J Røislien ${ }^{1,8}$ and J Hjelmesæth ${ }^{1}$ \\ ${ }^{1}$ Department of Medicine, Morbid Obesity Centre, Vestfold Hospital Trust, PO Box 2168, 3103 Tønsberg, Norway, ${ }^{2}$ Evjeklinikken AS, Evjemoen, 4735 \\ Evje, Norway, ${ }^{3}$ Department of Clinical Chemistry, Vestfold Hospital Trust, 3103 Tonsberg, Norway, ${ }^{4}$ Institute of Clinical Medicine, University of Tromse, \\ 9037 Tromsø, Norway, ${ }^{5}$ Section of Nephrology, Department of Medicine, Oslo University Hospital Rikshospitalet, O027 Oslo, Norway, ${ }^{6}$ Section of \\ Endocrinology, Department of Medicine, Oslo University Hospital Rikshospitalet, 0027 Oslo, Norway, ${ }^{7}$ Faculty of Medicine, University of Oslo, \\ 0318 Oslo, Norway and ${ }^{8}$ Department of Biostatistics, Institute of Basic Medical Sciences, University of Oslo, O317 Oslo, Norway \\ (Correspondence should be addressed to D Hofsø; Email: dag.hofso@siv.no)
}

\begin{abstract}
Objective: Weight reduction improves several obesity-related health conditions. We aimed to compare the effect of bariatric surgery and comprehensive lifestyle intervention on type 2 diabetes and obesityrelated cardiovascular risk factors.

Design: One-year controlled clinical trial (ClinicalTrials.gov identifier NCT00273104).

Methods: Morbidly obese subjects (19-66 years, mean (s.D.) body mass index $45.1 \mathrm{~kg} / \mathrm{m}^{2}$ (5.6), 103 women) were treated with either Roux-en-Y gastric bypass surgery $(n=80)$ or intensive lifestyle intervention at a rehabilitation centre $(n=66)$. The dropout rate within both groups was $5 \%$.

Results: Among the 76 completers in the surgery group and the 63 completers in the lifestyle group, mean (S.D.) 1-year weight loss was 30\% (8) and 8\% (9) respectively. Beneficial effects on glucose metabolism, blood pressure, lipids and low-grade inflammation were observed in both groups. Remission rates of type 2 diabetes and hypertension were significantly higher in the surgery group than the lifestyle intervention group; 70 vs $33 \%, P=0.027$, and 49 vs $23 \%, P=0.016$. The improvements in glycaemic control and blood pressure were mediated by weight reduction. The surgery group experienced a significantly greater reduction in the prevalence of metabolic syndrome, albuminuria and electrocardiographic left ventricular hypertrophy than the lifestyle group. Gastrointestinal symptoms and symptomatic postprandial hypoglycaemia developed more frequently after gastric bypass surgery than after lifestyle intervention. There were no deaths.

Conclusions: Type 2 diabetes and obesity-related cardiovascular risk factors were improved after both treatment strategies. However, the improvements were greatest in those patients treated with gastric bypass surgery.
\end{abstract}

European Journal of Endocrinology 163 735-745

\section{Introduction}

Obesity (body mass index (BMI) $\geq 30 \mathrm{~kg} / \mathrm{m}^{2}$ ) and its metabolic consequences, hyperglycaemia and high blood pressure, are major risk factors of cardiovascular morbidity and mortality $(1,2)$. Alongside tobacco usage and physical inactivity they represent the five leading global risks to mortality (3). In addition, several other cardiovascular risk factors, such as metabolic syndrome, albuminuria, left ventricular hypertrophy and low-grade inflammation, are all closely associated with obesity (4-7).

As the prevalence of obesity, and especially extreme obesity, has dramatically increased in the last few decades (8), so too has the usage of bariatric surgery to treat morbid obesity $\left(\mathrm{BMI} \geq 40 \mathrm{~kg} / \mathrm{m}^{2}\right.$ or BMI $\geq 35 \mathrm{~kg} / \mathrm{m}^{2}$ with at least one obesity-related comorbidity) (9). Currently, the most commonly performed bariatric procedure worldwide is the Roux-en-Y gastric bypass surgery (9). Several studies have documented how obesity surgery allows for large weight reduction and improvements in obesity-related conditions (10-15). Furthermore, comprehensive lifestyle intervention programmes have also demonstrated, although to a lesser extent, significant short-term weight reduction and improvements in cardiovascular risk factors in moderate to severely obese subjects (16-19). Importantly, increased physical activity, a pivotal component of all lifestyle intervention programmes, has been shown to have positive metabolic effects beyond weight reduction (20). However, only two controlled clinical trials have compared the effect of 
bariatric surgery and conventional therapy on the resolution of diabetes and cardiovascular risk factors $(10,11)$. In these studies, the average weight loss in the non-surgically treated groups was negligible. Not all morbidly obese subjects are suitable for bariatric surgery and therefore non-surgical treatment alternatives are needed.

The objective of this 1-year non-randomised controlled clinical trial was to compare the effect of Roux-en-Y gastric bypass surgery and a comprehensive lifestyle intervention programme on type 2 diabetes and obesity-related cardiovascular risk factors.

\section{Subjects and methods}

\section{Study design and participants}

This study was conducted at a public tertiary care centre at Vestfold Hospital Trust, Tønsberg, Norway.

Although preferable when conducting a clinical trial, we did not find randomisation to be appropriate. According to Norwegian guidelines, treatment seeking morbidly obese subjects should be offered either conservative or surgical therapy (21). We therefore considered it unethical to assign patients to surgery if they qualified for a lifestyle intervention programme and preferred this course of treatment to surgery. This stance also held vice versa.

In order to participate in the non-randomised controlled morbid obesity treatment, bariatric surgery versus intensive lifestyle intervention (MOBIL) study consecutive patients were pre-screened between December 2005 and May 2006 (Fig. 1). The MOBIL study aimed to address changes in several health outcomes related to obesity. Clinical and laboratory examinations were performed during pre-screening. Furthermore, patients who satisfied the criteria for bariatric surgery (22) and wanted either gastric bypass surgery or intensive lifestyle intervention were referred to a screening examination which included an oral glucose tolerance test, a somnography, pulmonary function tests, quality of life questionnaires and a structured dietary interview. All patients underwent a thorough assessment conducted by a multidisciplinary team consisting of an internist, a dietician and, in cases of surgery, a surgeon before treatment. These health professionals provided complete information about the possible risks and benefits of an operation and encouraged patients to incorporate their own values and preferences into the decision-making process. Each patient and their physician agreed together upon the most appropriate choice of therapy. The elapsed period of time between the pre-screening examination and the screening examination was 18 weeks (11); this did not differ significantly between the study groups $(P=0.063)$. By contrast, the time between the screening examination and either the date of surgery

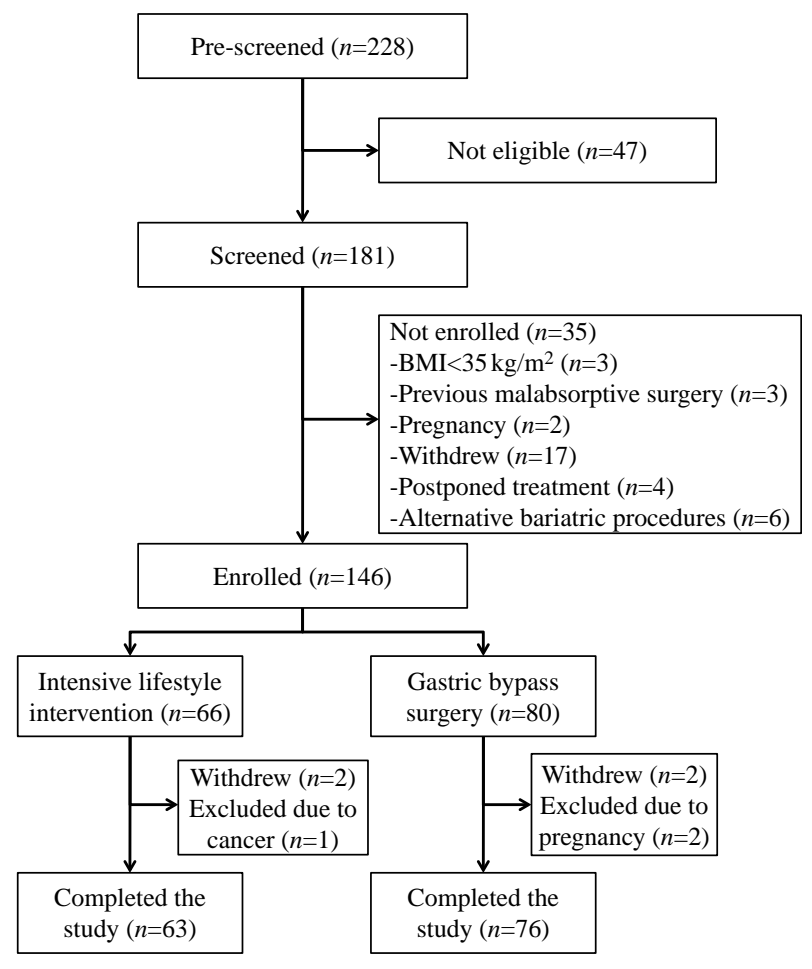

Figure 1 Flow of participants throughout the study.

or the start of lifestyle intervention was significantly longer in the surgery group than in the lifestyle group, 65 weeks (14) versus 19 weeks $(15) \quad(P<0.001)$. One-year follow-up was completed by June 2009. This article reports changes in weight, glucose- and lipid metabolisms, blood pressure, albuminuria, left ventricular hypertrophy, low-grade inflammation, energy intake and physical activity.

The study was approved by the regional ethics committee of what was formerly known as the Southern Norway Regional Health Authority. The study is registered in the ClinicalTrials.gov-registry under the unique trial number NCT00273104. Written informed consent was provided by all the participants.

\section{Intervention}

Both treatment groups were seen by an internist half yearly and by a dietician when required. Changes in medications were made on an individual basis by both the patients' general practitioner and by hospital physicians.

Patients in the surgical group completed a low-calorie diet (3.3-3.8 MJ/day) in 3-6 weeks preceding surgery. A Roux-en-Y gastric bypass surgery was performed laparoscopically in 74 of the 76 surgically treated patients. The gastric pouch was about $25 \mathrm{ml}$, while the intestinal limb lengths were measured as follows: alimentary limb, median 120 (range 80-250) cm; biliopancreatic limb, median 100 (range 50-170) cm; and common channel, variable length. The bariatric 
surgeons tended to choose longer limbs in the heaviest patients. After surgery, a standardised regimen of dietary supplements (23) and a proton pump inhibitor were prescribed to all patients. Patients with a high risk of venous embolism were prescribed low-molecular weight heparin. During follow-up, patients allocated to surgery were examined by a bariatric surgeon 6 weeks post surgery, while groups of patients were seen by a dietician quarterly. To optimise the result of the procedure patients were encouraged, both before and after the surgery, to normalise their eating behaviour and to increase their physical activity level.

The majority (59/63) of patients in the lifestyle group were referred to a rehabilitation centre specialising in the care of morbidly obese patients (Evjeklinikken). Using a cognitive approach the programme at this centre aimed to induce a weight loss of at least $10 \%$. Each patient was motivated to increase their physical activity and to normalise their eating habits. The 1-year lifestyle programme comprises four stays at the rehabilitation centre lasting for either 1 week or 4 weeks (Fig. 2). The daily programme was divided between organised physical activity (3-4 h) and different psychosocially oriented interventions. The interventions involved individual consultations with a medical doctor, a nutritionist, a physiotherapist and a trained nurse. Those leading the counselling interviews were trained in motivational interviewing, a client-centred counselling style that aims to invoke behaviour change. The patients also took part in group sessions focusing on emotional aspects of sedentary behaviour as well as classroom lessons on topics related to nutrition, physical activity and co-morbidities. No special diet or weight-loss drugs were prescribed, but patients were encouraged to follow the guidelines of the Norwegian National Council of Nutrition (24), which recommend that the daily intake of protein, fat, carbohydrate and alcohol should account respectively for 10-20, <30, 50-60 and <5\% of energy consumed. Outside of these stays, patients were contacted by phone once every 2 weeks. They were encouraged to self-monitor their eating habits and physical activities, as well as to visit their general practitioner for a consultation and weight control check once every 4 weeks. The remaining four participants were allocated to two rehabilitation centres with comparable intervention programmes. Fiftyfour patients $(86 \%)$ attended all scheduled centre visits.

\section{Outcome variables}

Demographic and clinical data were recorded on standardised forms. Height, weight and waist and hip circumferences were measured with patients in an upright position wearing light clothing and no shoes.
A $75 \mathrm{~g}$ oral glucose tolerance test was performed at $0800 \mathrm{~h}$ after an overnight fast. Type 2 diabetes was diagnosed in patients who used glucose-lowering agents or had fasting serum glucose $\geq 7.0 \mathrm{mmol} / \mathrm{l}$ and/or $2 \mathrm{~h}$ serum glucose $\geq 11.1 \mathrm{mmol} / \mathrm{l}(25)$. Remission of diabetes was defined as either partial (serum glucose levels below the diagnostic cut-off values and HbA1c $<6.5 \%$ ) or complete (fasting serum glucose $<5.6 \mathrm{mmol} / \mathrm{l}, 2 \mathrm{~h}$ glucose $<7.8 \mathrm{mmol} / \mathrm{l}$ and $\mathrm{HbA} 1 \mathrm{c}<6.2 \%$ ) in the absence of glucose-lowering agents (26). Combined remission rates (partial and complete) are presented unless otherwise specified.

Blood pressure was measured three times after at least $5 \mathrm{~min}$ rest. The average of the second and third measurements was registered. Patients using antihypertensive drugs, as well as those with systolic blood pressure $\geq 140 \mathrm{mmHg}$ and/or diastolic blood pressure $\geq 90 \mathrm{mmHg}(27)$ were categorised as having hypertension. Remission of hypertension was defined as blood pressure below the diagnostic cut-off values in the absence of anti-hypertensive drugs.

Metabolic syndrome was defined according to the modified ATP III criteria (28). Albuminuria was defined as present if the albumin to creatinine ratio was $\geq 2.5 \mathrm{mg} / \mathrm{mmol}$ in men and $\geq 3.5 \mathrm{mg} / \mathrm{mmol}$ in women (29). The product of QRS complex duration times Cornell voltage combination $\left(R_{\mathrm{aVL}}+S_{\mathrm{V} 3}\right.$, with $6 \mathrm{~mm}$ added in women) was used with a threshold value of $2440 \mathrm{~mm} \times \mathrm{ms}$ to identify electrocardiographic left ventricular hypertrophy (30). Regression of electrocardiographic left ventricular hypertrophy estimated by the Cornell voltage-duration product is known to predict regression of echocardiographic left ventricular hypertrophy (31).

Dietary intake and physical activity during the preceding year were assessed through structured interviews performed by registered dieticians. Data were recorded on an optically readable food frequency questionnaire (Department of Nutrition, University of Oslo, Norway). Similar questionnaires have been validated using weighted records (32). Questionnaire data were scanned using Teleform 10.0 (Cambridge, UK). Dietary intake was calculated using a database assembled from official food composition tables (Norwegian Nutrition Council, 1995). Calculations were computer driven (Kostberegningssystem 6.0; University of Oslo, Norway). Time spent performing light (e.g. casual walking), moderate (e.g. brisk walking) and vigorous (e.g. jogging) intensity aerobic physical activities in periods of $10 \mathrm{~min}$ or more was recorded. Participants who performed $150 \mathrm{~min}$ or more per week of moderately intense aerobic physical activities were considered to be physically active, as

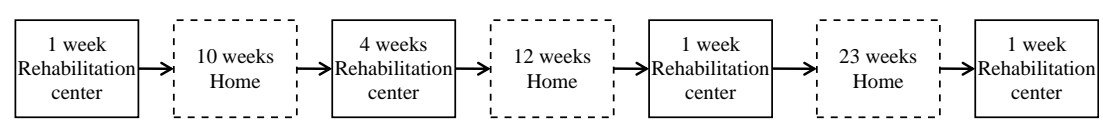

center
Figure 2 Schedule of stays during the 1 -year lifestyle programme at Evjeklinikken. 
were those participants who performed $60 \mathrm{~min}$ or more per week of vigorously intense aerobic physical activities (33).

Perioperative (first 30 days) and late (after 30 days) complications were recorded in each patient's record file. In addition, all medical emergencies, hospitalisations and gastrointestinal side effects were reported on standardised self-report questionnaires. Reported symptomatic postprandial hypoglycaemia was documented by blood glucose $<2.8 \mathrm{mmol} / \mathrm{l}$ (34). Complications and medical emergencies not recorded in each patient's record file at our hospital were verified by reports from other institutions.

\section{Laboratory analyses}

Blood samples were collected either in the fasting state or during the oral glucose tolerance test. Samples clotted $30 \mathrm{~min}$ at room temperature, and serum was separated by centrifugation. Analyses of blood lipids and glucose were performed by dry reagent slide technology on the Vitros 950 Analyzer until November 2006 and the Vitros FS 5.1 Analyzer (Ortho-Clinical Diagnostics, New York, NY, USA) thereafter. HbA1c was analysed using HPLC on Tosoh HLC-723 G7 (Tosoh Corporation, Tokyo, Japan).

Serum samples collected during the oral glucose tolerance test were either stored at $-80^{\circ} \mathrm{C}$ or analysed on the day of collection (glucose). Insulin, C-reactive protein and adiponectin were measured in stored serum obtained before the glucose ingestion. Insulin was analysed using an RIA (Millipore Corporation, Billerica, MA, USA), whereas C-reactive protein and adiponectin were analysed using enzyme immunoassays (R\&D systems, Minneapolis, MN, USA). All samples were measured in duplicate. The intra- and inter-assay coefficients of variation were $<10 \%$ for all assays.

Albumin and creatinine in urine were analysed using Konelab 60i (Thermo Electron Corporation, Helsinki, Finland) until August 2008 and Vitros FS 5.1 Chemistry System thereafter.

\section{Statistical analysis}

The sample size of the MOBIL study was calculated (80\% statistical power, $\alpha$-level of 0.05 and equal distribution to the treatment groups) based on anticipated remission rates of type 2 diabetes and obstructive sleep apnoea. Given remission rates of type 2 diabetes of $70 \%$ in the surgery group and $20 \%$ in the lifestyle group, at least 30 subjects with type 2 diabetes were required. Expecting a prevalence of type 2 diabetes of $25 \%$ and a dropout rate of $30 \%$ from the screening examinations, a minimum of 172 subjects were required for screening.

Data are presented as mean (s.D.) or number (\%) unless otherwise specified. Skewed data were transformed using natural logarithms to approximate normality. Between-group comparisons at baseline were analysed using independent samples $t$-test or Mann-Whitney $U$ test for continuous variables and $\chi^{2}$ or Fisher's exact test for categorical variables. Withingroup comparisons were performed using paired samples $t$-test or repeated measures ANOVA for continuous variables and McNemar test for dichotomised variables. Between-group changes in outcome variables were assessed using logistic and linear regression analyses, analysis of covariance, repeated measures ANOVA and Fisher's exact test. Furthermore, changes in categorical and continuous variables were adjusted for baseline differences. In addition, continuous variables were, in the entire study population, adjusted for gender, age, BMI at baseline and changes in relevant medication. Regression analyses were used to identify predictors of remission of diabetes and hypertension and to explore the independent effects of several variables on changes in $\mathrm{HbA1c}$ and blood pressure. For each variable, only subjects who had values available at both baseline and follow-up are presented and included in the analyses. There were $<5 \%$ missing and/or excluded data unless otherwise noted. The significance level was $P<0.05$. Statistical analyses were performed using SPSS 16.0 (SPSS Inc., Chicago, IL, USA).

\section{Results}

\section{Baseline characteristics of participants}

Patient flow throughout the study is shown in Fig. 1. Of the 146 patients included, 80 chose to have surgery and 66 chose to participate in a lifestyle intervention programme. The completion rate was 95\%. Baseline characteristics of the participants who completed the study are shown in Table 1. No significant differences were found between the two study groups in terms of sex, ethnicity, obesity-related comorbidities or the usage of weight-loss drugs or statins. However, patients who chose gastric bypass surgery were on average 4 years younger and $12 \mathrm{~kg}$ heavier than those in the lifestyle group.

\section{Weight reduction}

Weight changes in the two treatment groups during the study are shown in Fig. 3A. Mean (s.D.) percentage 1-year weight reduction was $30 \%(8)$ in the surgery group and $8 \%(9)$ in the lifestyle group (within-groups both $P<0.001$ and between-groups $P<0.001$ ). This corresponds to a mean (S.D.) loss of excess weight above $25 \mathrm{~kg} / \mathrm{m}^{2}$ of $67 \%$ (18) and $20 \%$ (23) $(P<0.001)$ respectively.

The cumulative distribution of percentage weight change in the two treatment groups is shown in Fig. 3B. Within the lifestyle group, $62 \%$ lost $\geq 5 \%$ of their initial 
Table 1 Participant characteristics at baseline. Data are given as mean (S.D.), median (range), or $n$ (\%). Differences between categorical data were determined using either $\chi^{2}$ or Fisher's exact test, whilst independent sample $t$-test or Mann-Whitney $U$ test were used for continuous data.

\begin{tabular}{|c|c|c|c|}
\hline & $\begin{array}{c}\text { Surgery } \\
(n=76)\end{array}$ & $\begin{array}{l}\text { Lifestyle } \\
(n=63)\end{array}$ & $P$ value \\
\hline Age (years) & $42.8(10.5)$ & $47.0(11.0)$ & 0.023 \\
\hline Gender (female) & 53 (70\%) & 44 (70\%) & 0.989 \\
\hline Caucasian & $74(97 \%)$ & $61(97 \%)$ & 0.849 \\
\hline Type 2 diabetes & $20(26 \%)$ & $18(29 \%)$ & 0.766 \\
\hline $\begin{array}{l}\text { Duration of type } \\
2 \text { diabetes (years) }\end{array}$ & $1(0$ to 31$)$ & 0 (0 to 16$)$ & 0.235 \\
\hline Hypertension & $41(54 \%)$ & $40(64 \%)$ & 0.256 \\
\hline Metabolic syndrome & $58(76 \%)$ & $44(70 \%)$ & 0.390 \\
\hline Albuminuria & $11(15 \%)^{a}$ & $7(13 \%)^{b}$ & 0.745 \\
\hline Left ventricular hypertrophy & $13(17 \%)^{\mathrm{c}}$ & $7(11 \%)^{d}$ & 0.319 \\
\hline Coronary heart disease & $5(7 \%)$ & $4(7 \%)$ & 1.000 \\
\hline Weight (kg) & $137(21)$ & $125(20)$ & 0.001 \\
\hline Body mass index $\left(\mathrm{kg} / \mathrm{m}^{2}\right)$ & $46.7(5.7)$ & $43.3(5.0)$ & $<0.001$ \\
\hline Waist circumference $(\mathrm{cm})$ & $135(13)$ & $129(12)$ & 0.009 \\
\hline Waist-to-hip ratio & $0.99(0.09)$ & $0.97(0.09)$ & 0.447 \\
\hline Glucose, fasting $(\mathrm{mmol} / \mathrm{l})$ & $6.8(2.3)$ & $6.4(1.7)$ & 0.520 \\
\hline Glucose, $2 \mathrm{~h}(\mathrm{mmol} / \mathrm{l})$ & $7.5(3.4)^{\mathrm{e}}$ & $7.6(3.1)^{f}$ & 0.877 \\
\hline Insulin, fasting (pmol/l) & $247(106)$ & 228 (111) & 0.254 \\
\hline $\mathrm{HbA1c}(\%)$ & $5.9(1.1)$ & $5.7(0.8)$ & 0.520 \\
\hline Systolic BP (mmHg) & $133(18)$ & $135(16)$ & 0.510 \\
\hline Diastolic BP (mmHg) & $83(11)$ & $83(10)$ & 0.857 \\
\hline Pulse pressure $(\mathrm{mmHg})$ & $51(13)$ & $52(14)$ & 0.476 \\
\hline Total cholesterol (mmol/l) & $5.1(1.1)$ & $5.2(1.0)$ & 0.724 \\
\hline LDL cholesterol (mmol/l/) & $3.1(0.9)$ & $3.3(0.9)$ & 0.226 \\
\hline HDL cholesterol (mmol/l) & $1.2(0.3)$ & $1.2(0.3)$ & 0.457 \\
\hline Triglycerides $(\mathrm{mmol} / \mathrm{l})$ & $1.8(1.0)$ & $1.5(0.9)$ & 0.013 \\
\hline C-reactive protein (mg/l) & $2.9(2.4)$ & $3.2(3.9)$ & 0.408 \\
\hline Adiponectin $(\mu \mathrm{g} / \mathrm{ml})$ & $5.7(3.2)$ & $5.8(3.4)$ & 0.721 \\
\hline Energy intake (MJ/day) & $11.2(4.5)^{g}$ & $12.0(3.8)^{\mathrm{h}}$ & 0.293 \\
\hline Physically active & $7(10 \%)^{g}$ & $10(18 \%)^{\mathrm{h}}$ & 0.179 \\
\hline Currently smoking & $21(28 \%)$ & $21(33 \%)$ & 0.466 \\
\hline Weight loss drugs & $4(5 \%)$ & $2(3 \%)$ & 0.689 \\
\hline Statins & $10(13 \%)$ & $7(11 \%)$ & 0.798 \\
\hline
\end{tabular}

LDL, low density lipoprotein, HDL, high density lipoprotein.

${ }^{\mathrm{a}} n=72 ; \quad{ }^{\mathrm{b}} n=53 ;{ }^{\mathrm{c}} n=75 ;{ }^{\mathrm{d}} n=62 ;{ }^{\mathrm{e}} n=64 ; \quad{ }_{\mathrm{f}} n=55 ; \quad{ }^{\mathrm{g}} n=73 ;{ }^{\mathrm{h}} n=55$; ${ }^{i} \geq 150$ min of moderately intense or $\geq 60 \mathrm{~min}$ of vigorously intense aerobic physical activity per week.

weight, while $38 \%$ lost $\geq 10 \%$ of their initial weight. Within the surgery group, all subjects experienced a weight reduction $>10 \%$ of their initial weight.

\section{Changes in measures of obesity, glucose metabolism, blood pressure, lipids and inflammatory markers}

With the exception of pulse pressure, changes in anthropometric measures, blood pressures and biochemical risk factors were significantly greater in the surgery group than in the intensive lifestyle group (Table 2). Both treatment groups experienced a significant reduction in all measures of obesity, glucose metabolism, blood pressure, total and low-density lipoprotein cholesterol, triglycerides and C-reactive protein during follow-up (all $P \leq 0.034$ ). Adiponectin increased significantly in both treatment groups (both $P<0.001$ ), whereas high-density lipoprotein cholesterol increased significantly only in the surgery group $(P<0.001)$.

Subgroup analyses including subjects with $\geq 10 \%$ weight reduction showed that multi-adjusted (gender, age, BMI, baseline value and change in relevant medications) between-group changes in $\mathrm{HbAlc}$ and systolic and diastolic blood pressures did not differ significantly between the surgically and the conservatively treated groups (mean $(95 \% \mathrm{CI}) 0.0(-0.2$ to 0.2$)$ $\%, P=0.965 ;-2(-7$ to 4$) \mathrm{mmHg}, P=0.536$; and -3 ( -7 to 1$) \mathrm{mmHg}, P=0.115$, respectively).

Regression analyses, including percentage weight change, treatment choice, gender, age, BMI, baseline value and change in relevant medication as independent variables, showed that weight loss, but not treatment choice, was significantly associated with reduction in $\mathrm{HbA} 1 \mathrm{c}$ and systolic blood pressure, but not diastolic blood pressure $\left(R^{2}=0.712, \beta=0.206\right.$, $P=0.008 ; R^{2}=0.580, \quad \beta=0.313, P=0.001$; and $\left.R^{2}=0.423, \beta=0.140, P=0.210\right)$.
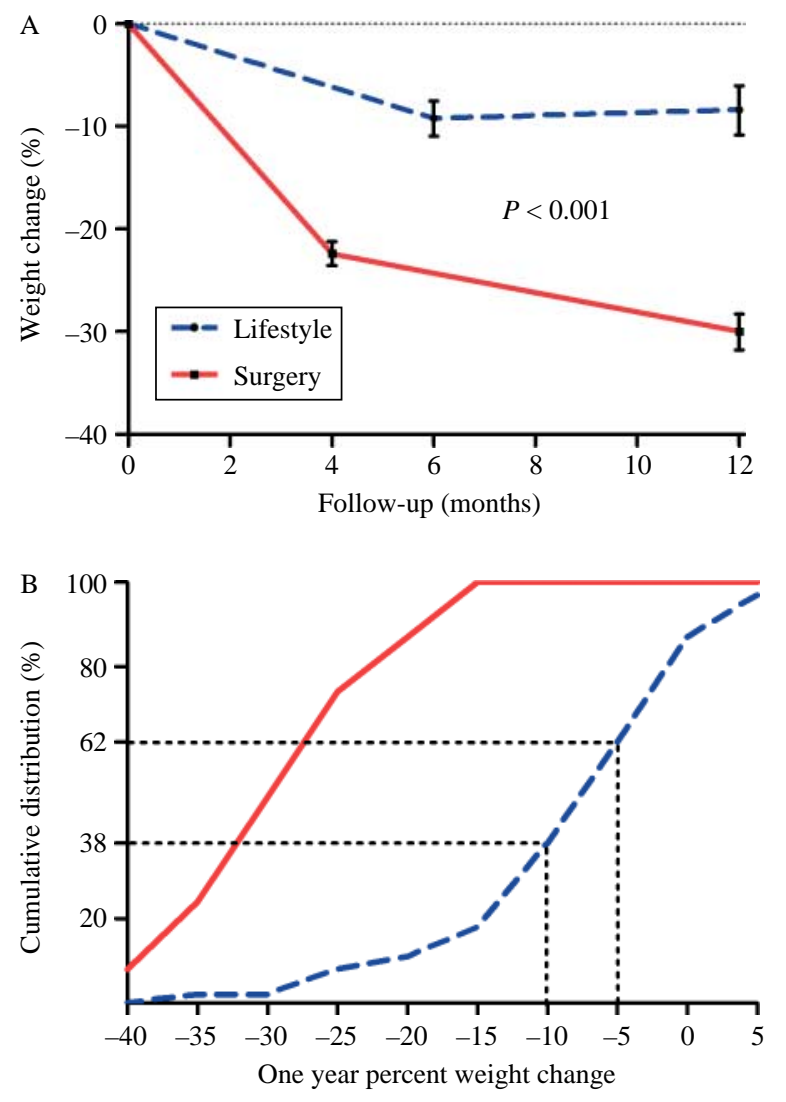

Figure 3 Mean $(95 \% \mathrm{Cl})$ percentage weight change during follow-up (A) and distribution of 1-year changes in weight (B) within the surgery and lifestyle groups. Repeated measures ANOVA was used to compare the change in weight between the two study groups. 
Table 2 Changes from baseline in various continuous variables. Unadjusted within-group changes are given as mean (s.D.). Adjusted between-group differences and corresponding $P$ value were calculated with the use of analysis of covariance and presented as mean (95\% $\mathrm{Cl}$ ). All between-group differences were adjusted for gender, age, baseline body mass index, and baseline values. Furthermore, fasting and 2-h glucose, insulin and $\mathrm{HbA} 1 \mathrm{c}$ were adjusted for change in the usage of glucose lowering agents; systolic and diastolic blood pressure and pulse pressure were adjusted for change in the usage of anti-hypertensive drugs; and total cholesterol, low and high density lipoprotein cholesterol, and triglycerides were adjusted for the change in the usage of statins.

\begin{tabular}{|c|c|c|c|c|}
\hline & Surgery $(n=76)$ & Lifestyle $(n=63)$ & $\begin{array}{l}\text { Adjusted between-group } \\
\text { difference, mean }(95 \% \mathrm{Cl})\end{array}$ & $P$ value \\
\hline Weight $(\mathrm{kg})^{\mathrm{a}}$ & $-41.3(13.1)$ & $-10.7(12.0)$ & $-27.6(-31.7$ to -23.5$)$ & $<0.001$ \\
\hline Body mass index $\left(\mathrm{kg} / \mathrm{m}^{2}\right)$ & $-14.0(4.1)$ & $-3.7(4.2)$ & $-9.4(-10.8$ to -8.0$)$ & $<0.001$ \\
\hline Waist circumference $(\mathrm{cm})^{a}$ & $-30.3(10.5)$ & $-10.3(10.6)$ & $-17.8(-21.3$ to -14.4$)$ & $<0.001$ \\
\hline Waist-to-hip ratio & $-0.06(0.06)$ & $-0.01(0.07)$ & $-0.05(-0.07$ to -0.03$)$ & $<0.001$ \\
\hline Glucose, fasting $(\mathrm{mmol} / \mathrm{l})$ & $-1.9(2.0)$ & $-0.8(1.0)$ & $-0.8(-1.1$ to -0.5$)$ & $<0.001$ \\
\hline Glucose, $2 \mathrm{~h}(\mathrm{mmol} / \mathrm{l})$ & $-4.2(3.2)$ & $-1.6(1.9)$ & $-2.4(-3.0$ to -1.8$)$ & $<0.001$ \\
\hline Insulin, fasting (pmol/l/) & $-142(96)$ & $-53(84)$ & $-77(-100$ to -54$)$ & $<0.001$ \\
\hline $\mathrm{HbA1c}(\%)$ & $-0.4(0.9)$ & $-0.1(0.5)$ & $-0.2(-0.3$ to -0.0$)$ & 0.047 \\
\hline Systolic blood pressure $(\mathrm{mmHg})$ & $-14(16)$ & $-10(15)$ & $-4(-8$ to -0$)$ & 0.028 \\
\hline Diastolic blood pressure $(\mathrm{mmHg})$ & $-12(10)$ & $-6(11)$ & $-5(-8$ to -2$)$ & 0.002 \\
\hline Pulse pressure $(\mathrm{mmHg})$ & $-2(14)$ & $-4(12)$ & $1(-3$ to 4$)$ & 0.760 \\
\hline Total cholesterol $(\mathrm{mmol} / \mathrm{l})$ & $-1.2(1.1)$ & $-0.7(0.8)$ & $-0.4(-0.6$ to -0.2$)$ & $<0.001$ \\
\hline LDL cholesterol (mmol/l) & $-1.0(0.8)$ & $-0.5(0.7)$ & $-0.5(-0.7$ to -0.4$)$ & $<0.001$ \\
\hline HDL cholesterol ( $\mathrm{mmol} / \mathrm{l})$ & $0.2(0.3)$ & $0.0(0.2)$ & $0.2(0.2$ to 0.3$)$ & $<0.001$ \\
\hline Triglycerides $(\mathrm{mmol} / \mathrm{l})$ & $-0.9(1.0)$ & $-0.4(0.8)$ & $-0.2(-0.3$ to -0.0$)$ & 0.014 \\
\hline C-reactive protein $(\mathrm{mg} / \mathrm{l})$ & $-2.1(2.2)$ & $-1.4(3.6)$ & $-1.0(-1.5$ to -0.6$)$ & $<0.001$ \\
\hline Adiponectin $(\mu \mathrm{g} / \mathrm{ml})$ & $3.9(3.8)$ & $1.8(3.2)$ & $2.0(1.0$ to 3.0$)$ & $<0.001$ \\
\hline Energy intake (MJ/day) & $-4.7(4.5)$ & $-3.5(3.5)$ & $-1.7(-2.3$ to -1.0$)$ & $<0.001$ \\
\hline
\end{tabular}

LDL, low density lipoprotein, HDL, high density lipoprotein.

${ }^{\mathrm{a}}$ Not adjusted for body mass index.

All participants had $2 \mathrm{~h}$ glucose $>2.8 \mathrm{mmol} / \mathrm{l}$ at baseline. In contrast, $2(4 \%)$ patients in the lifestyle group and $15(23 \%)$ patients in the surgery group had $2 \mathrm{~h}$ glucose $<2.8 \mathrm{mmol} / \mathrm{l}$ after the intervention $(P=0.003)$.

\section{Type 2 diabetes and hypertension}

Among participants with type 2 diabetes, HbAlc was reduced from $6.6 \%(1.0)$ to $6.3 \%(0.9)$ in the lifestyle group and from $7.1 \%(1.5)$ to $5.8 \%(0.5)$ in the surgery group (adjusted between-group difference, $P=0.003$ ). Moreover, the hypertensive subgroups' systolic blood pressure declined from $144 \mathrm{mmHg}$ (16) to $125 \mathrm{mmHg}$ (12) after the surgical procedure and from $143 \mathrm{mmHg}$ (15) to $130 \mathrm{mmHg}$ (14) after the lifestyle intervention (adjusted between-group differences, $P=0.061$ ). Furthermore, the number of diabetic subjects using glucose-lowering agents dropped (from 11 to 6) in the surgery group and increased (from 6 to 10) in the lifestyle group (between-group difference, $P=0.017$ ). In contrast, the reduction in the number of hypertensive participants using anti-hypertensive drugs did not differ significantly between the surgery group (from 24 to 21) and the lifestyle group (from 30 to 25) (between-group difference, $P=1.00$ ).

The remission rates of type 2 diabetes and hypertension related to weight change after gastric bypass surgery and lifestyle intervention are shown in Fig. 4 . The remission rates of both conditions were significantly higher after surgical treatment than after lifestyle intervention. Complete remission of type 2 diabetes was significantly more frequent in the surgery group than in the lifestyle group $(11 / 14$ vs $0 / 6, P=0.002)$.

Multiple regression analyses demonstrated that no usage of glucose-lowering agents and anti-hypertensive drugs at baseline were, independent of percentage weight change and treatment choice, associated with remission of type 2 diabetes $(P=0.023)$ and hypertension $(P<0.001)$. In addition, univariate linear regression analyses showed that greater reductions in $\mathrm{HbA1c}$ and systolic blood pressure were associated with surgical treatment $(\beta=-0.408, P=0.011$ and $\beta=-0.187, P=0.096$ respectively). Inclusion of percentage weight change in the regression analyses showed that weight loss mediated the effects of treatment choice on these outcomes $(\beta=0.406, P=0.160$ and $\beta=0.142, P=0.410$ respectively). Furthermore, weight loss was significantly associated with reductions in $\mathrm{HbA1c}$ and systolic blood pressure $(\beta=0.926$, $P=0.002$ and $\beta=0.423, P=0.016$ respectively).

\section{Metabolic syndrome, albuminuria and left ventricular hypertrophy}

The changes in the number of individuals with metabolic syndrome $(-44$ vs -14$)$, albuminuria ( -7 vs 3$)$ and left ventricular hypertrophy ( -10 vs -2 ) were significantly greater in the surgery group than in the lifestyle group (Fig. 5). The prevalence of metabolic syndrome reduced significantly in both treatment groups (both $P \leq 0.001$ ), while the 


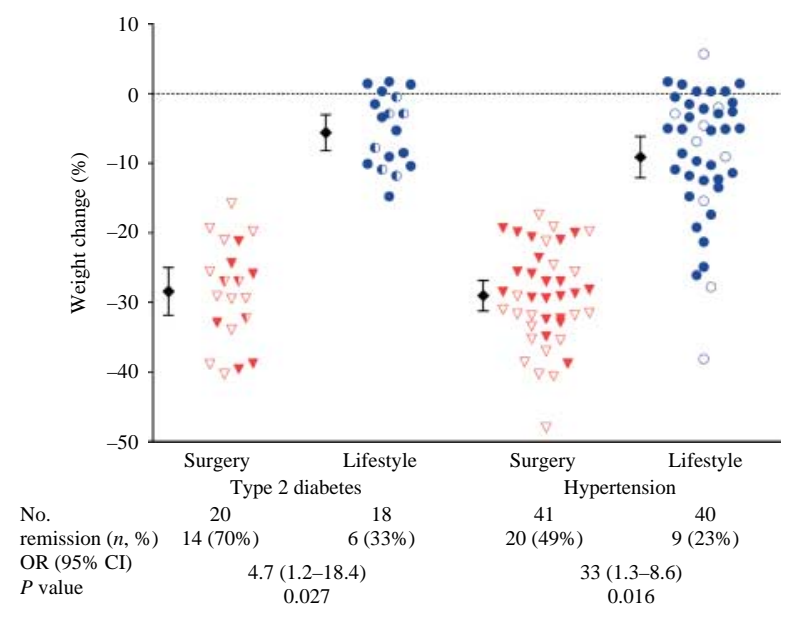

Figure 4 Remission of type 2 diabetes and hypertension at 1 year correlated to percentage weight change in individuals treated with gastric bypass surgery or intensive lifestyle intervention. Red triangles represent patients treated with gastric bypass surgery, while blue circles represent subjects who chose lifestyle intervention. Open triangles/circles denote complete remission of type 2 diabetes and remission of hypertension, half filled triangles/circles denote partial remission of type 2 diabetes and filled triangles/circles denote no remission. For definitions of partial and complete remission of type 2 diabetes, see 'Subjects and methods' section. Mean percentage weight changes (black diamonds) within the groups are shown with bars extending from the diamonds representing $95 \% \mathrm{Cl}$. Odds ratios (OR) were calculated using logistic regression analyses. Combined (partial and complete) remission of type 2 diabetes was used in the analysis.

prevalence of left ventricular hypertrophy was significantly reduced in only the surgery group $(P=0.002)$. In contrast, the prevalence of albuminuria did not change significantly within either treatment group.

\section{Lifestyle and medications}

Although both treatment groups reported significantly lower energy intake at 1 year than at baseline (both $P<0.001)$, the reduction was significantly greater in the surgery group than in the lifestyle group (Table 2). The number of subjects in the surgery group and lifestyle group which either moved from being inactive to active (12 vs 18 ), stayed inactive or active ( 57 vs 32 ) or moved from being active to inactive (4 vs 5 ) differed significantly between the groups (Fig. 6). Overall, there was a greater increase in the physical activity level of the lifestyle group than the surgery group. However, the median (range) time spent performing physical activities with moderate or vigorous intensity after the interventions did not differ significantly between the surgery and lifestyle groups, 20 (0-510 min) versus 65 (0-660 min), $P=0.148$.

Usage of weight-loss medications was stopped in all surgically treated patients and started in only one patient in the lifestyle group. The change in the number of individuals using statins did not differ significantly between the surgery and the lifestyle (10 vs 3, $P=0.114)$.

\section{Last observation carried forward}

In additional calculations, missing values were replaced by the last observed value of the respective variable (data not shown). These results did not alter the conclusions of the study.

\section{Adverse events}

Median (range) post-operative stay was 2 (1-9) days. Perioperative complications in the surgery group included one gastrojejunal anastomotic leakage, which was successfully re-operated on during the first post-operative day, one major bleeding at the site of the trocar insertion, which needed a blood transfusion, and two pneumonias treated effectively with antibiotics.

Late complications in the surgery group included four patients with symptomatic cholelithiasis (imaging verified), two patients with marginal ulcers, five patients with postprandial hypoglycaemia, one patient with a fracture of the fifth right proximal phalange and one patient with myocardial infarction. In the lifestyle group, one patient was diagnosed with breast cancer, one patient suffered a right ankle fracture that was treated with a stabilising cast and complicated by a deep venous thrombosis and one patient developed cholelithiasis. There were no deaths.

In total, $48 \%$ (33/69) of patients in the surgery group and $7 \%(4 / 59)$ of patients in the lifestyle group developed gastrointestinal symptoms, including abdominal pain, nausea, vomiting, diarrhoea and constipation $(P<0.001)$.

\section{Discussion}

To our knowledge, this is the first controlled, clinical trial that has sought to evaluate the effects of gastric bypass surgery and intensive lifestyle intervention on cardiovascular risk factors. When compared with the lifestyle group, the surgery group had higher remission rates

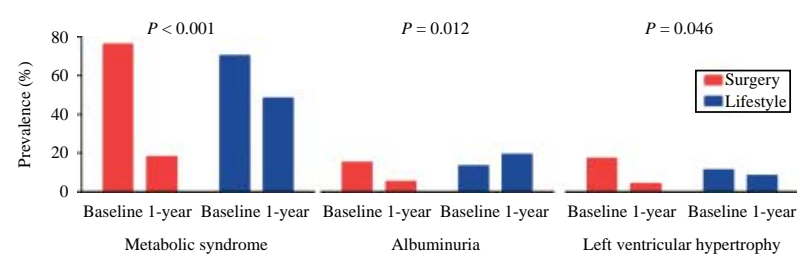

Figure 5 The prevalence of metabolic syndrome, albuminuria and left ventricular hypertrophy in the treatment groups at both baseline and 1-year follow-up. Between-group differences at 1 year were adjusted for differences in prevalence at baseline using logistic regression analyses. $P$ values are for comparisons between surgery and lifestyle groups. 

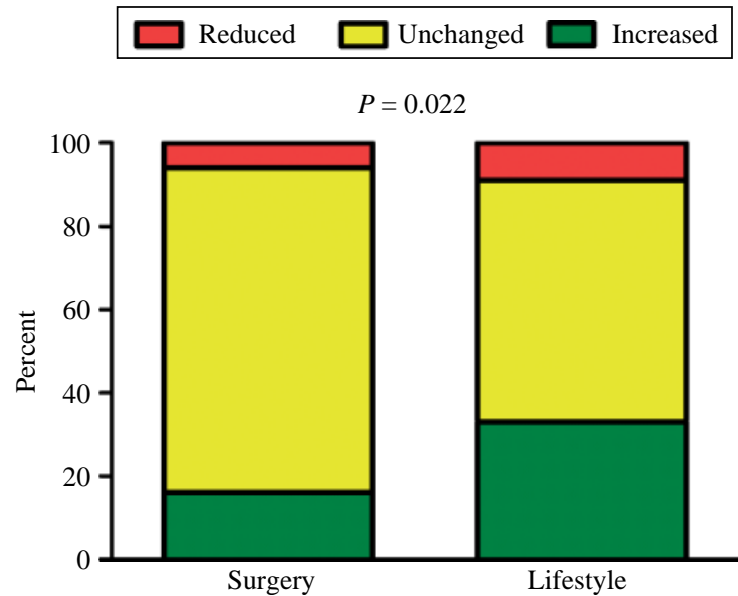

Figure 6 Change in physical activity during 1-year follow-up. The proportion of participants who went from being physically active ( $\geq 150 \mathrm{~min}$ of moderate or $\geq 60 \mathrm{~min}$ of vigorous aerobic physical activity per week) to inactive (reduced) were still physically active or inactive (unchanged) or went from being physically inactive to active (increased). The changes were adjusted for baseline activity level using linear regression analysis. $P$ value is for comparisons between surgery and lifestyle groups.

of type 2 diabetes and hypertension, as well as greater reductions in the prevalence of metabolic syndrome, albuminuria and left ventricular hypertrophy. Notably, intensive lifestyle intervention was also associated with favourable changes in measures of glucose metabolism, blood pressure, lipids and low-grade inflammation.

\section{Strengths and weaknesses of the study}

The strengths of this study include the prospective design, the fact that the control group obtained a significant weight loss from lifestyle intervention and the high participant completion rate. Limitations of the study include the lack of randomisation (addressed in 'Subjects and methods' section), a larger intervention delay in the surgery group and the short-term followup. Furthermore, the diagnoses of type 2 diabetes and hypertension were, in the absence of hypoglycaemic or anti-hypertensive drugs, based on only one measurement and not repeated measurements as recommended $(25,27)$. Finally, the majority of the study population was of Europoid origin, meaning that the results of this study cannot be generalised to include other ethnic groups.

\section{Type 2 diabetes and hypertension}

Both the case controlled Swedish Obese Subjects (SOS) study (10) and the Australian randomised controlled clinical trial (11) demonstrated that 2 year remission rates of type 2 diabetes were significantly higher in patients treated with bariatric surgery than in conservatively treated controls. The SOS study also reported higher remission rates of hypertension in the surgery group. Our study extends these findings by showing that morbidly obese patients treated with gastric bypass surgery were more likely to achieve remission of type 2 diabetes and hypertension than those who participated in a comprehensive lifestyle intervention programme. In addition to a shorter intervention period, our study differs from these previous trials in several ways. First, in contrast with our standardised and comprehensive lifestyle programme, the above two studies are notable for the fact that non-surgical treatment varied considerably and that weight loss was negligible. Second, our surgical procedure was gastric bypass, whereas purely restrictive, bariatric procedures were mainly implemented in the two other studies. Accordingly, the average 1-year weight reduction was more pronounced in our surgical group. Third, our definition of remission of type 2 diabetes differed slightly from the previous studies. Finally, the Australian study differed in the sense that it only included those patients who had type 2 diabetes of $<2$ years duration and a BMI of between 30 and $40 \mathrm{~kg} / \mathrm{m}^{2}$. Nevertheless, despite these differences, the remission rate of diabetes in our surgical group was nearly identical with rates in these previous studies (70 vs 71 and $72 \%$ ). Furthermore, while hypertension was resolved in approximately half the surgical patients in our study, it did so in only one-third of the patients in the SOS study.

Our study shows that weight reduction, and not treatment choice, predicted improvement in glycaemic control and systolic blood pressure. Furthermore, most of the beneficial metabolic effects were observed after a weight reduction of $\geq 10 \%$. Accordingly, the metabolic effect of gastric bypass surgery seems to be mediated through weight reduction.

Despite extensive weight loss, type 2 diabetes and hypertension in a substantial number of surgically treated patients were not resolved. In contrast, remission of these conditions was observed in some lifestyle group patients despite only modest weight reduction. These findings might be explained by differences in the severity of the conditions and the possible beneficial effect of increased physical activity. Indeed, the absence of glucose-lowering drugs and anti-hypertensive medication independently predicted remission of both diabetes and hypertension. Furthermore, compared with subjects treated with surgery, a significantly higher proportion of the participants in the lifestyle group became physically active.

Both blood glucose and blood pressure are continuous risk factors for death and cardiovascular disease $(35,36)$. The observed decline in these measures in both intervention groups may therefore have positive health effects. Conversely, the five cases of symptomatic postprandial hypoglycaemia and the large proportion $(23 \%)$ of patients with $2 \mathrm{~h}$ glucose $<2.8 \mathrm{mmol} / \mathrm{l}$ in the gastric bypass group raise some concerns. Severe postprandial hypoglycaemia after Roux-en-Y gastric 
bypass surgery has been reported previously and post-surgical nesidioblastosis may contribute to this complication (37). Furthermore, severe and symptomatic hypoglycaemia in type 2 diabetic subjects has been shown to be associated with increased mortality (38). Consequently, it cannot be excluded that the reduction in $2 \mathrm{~h}$ glucose observed after Roux-en- $\mathrm{Y}$ gastric bypass surgery may also have negative long-term health effects.

\section{Other cardiovascular risk factors}

Surgical therapy was superior to lifestyle intervention both in terms of the resolution of metabolic syndrome, left ventricular hypertrophy and microalbuminuria, as well as with respect to improvements in inflammatory markers. In line with previous studies, we report that weight reduction was associated with resolution of metabolic syndrome $(11,17)$, beneficial changes in C-reactive protein and adiponectin levels (16) and reduction in left ventricular mass (12). Improvement in all renal parameters, including albuminuria, has been reported after gastric bypass surgery (13). Similarly, weight reduction after lifestyle intervention has been reported to resolve albuminuria (17). In contrast to this finding and closer to our own results, modest weight reduction in the intensive lifestyle group of the Diabetes Prevention Program did not reduce albumin excretion significantly (39).

\section{Clinical and research implications of the work}

In sum, we have shown that gastric bypass surgery is more effective than intensive lifestyle intervention in terms of improving type 2 diabetes and obesity-related cardiovascular risk factors. However, morbidly obese patients treated with lifestyle intervention also experienced significant and meaningful improvements in most cardiovascular risk factors, and significantly more patients in the lifestyle group than the surgery group became physically active. Gastric bypass surgery was associated with a significantly higher risk of gastrointestinal symptoms and complications as reported previously (40). Furthermore, although a specified set of dietary supplements seems to prevent vitamin deficiencies after gastric bypass surgery (23), several deficiencies may occur if an inadequate supplementation is prescribed (41). Finally, even though reduced overall mortality after bariatric surgery has been reported (42), it is still unclear whether short-term improvement in obesity-related cardiovascular risk factors translates into long-term reduced cardiovascular morbidity and mortality. Our results indicate that when treating morbidly obese patients, gastric bypass surgery should not, despite its ability to improve risk factors, be considered the default course of treatment. Rather, both patient and physician should consider the possible side effects of this treatment, and, where appropriate, take up alternative conservative treatments. Indeed, intensive behavioural intervention has been shown to result in long-term weight reduction in some patients (43), while improved physical fitness is known to reduce all cause mortality (44). Moreover, it should be emphasised that if the success of bariatric surgery is to be optimised then behavioural changes are also necessary (45). Future studies comparing surgery and non-surgical treatment programmes should address the effect of these treatments on long-term cardiovascular morbidity and mortality.

\section{Declaration of interest}

T I Karlsen is one of the founders of Evjeklinikken $\mathrm{A} / \mathrm{S}$ and is a former board member (until November 2008) and stockholder (until August 2009). He is now a PhD student at the Morbid Obesity Centre and is supported financially by Evjeklinikken A/S. All the other authors declare that there is no conflict of interest that could be perceived as prejudicing the impartiality of the research reported.

\section{Funding}

The study was supported by grants from Novo Nordisk A/S (to D Hofsø) and the National Resource Centre for Women's Health, Oslo University Hospital Rikshospitalet (to L K Johnson).

\section{Acknowledgements}

We thank Berit Mossing Bjørkås, Heidi Omre Fon and Linda Mathisen for their assistance with sampling and logistics, and Matthew McGee for proof reading the manuscript.

\section{References}

1 Flegal KM, Graubard BI, Williamson DF \& Gail MH. Excess deaths associated with underweight, overweight, and obesity. Journal of the American Medical Association 2005293 1861-1867. (doi:10. 1001/jama.293.15.1861)

2 Must A, Spadano J, Coakley EH, Field AE, Colditz G \& Dietz WH. The disease burden associated with overweight and obesity. Journal of the American Medical Association $1999 \mathbf{2 8 2}$ 1523-1529. (doi:10.1001/jama.282.16.1523)

3 World Health Organization. Global health risks: mortality and burden of disease attributable to selected major risks. Available from: http://www.who.int/healthinfo/global_burden_disease/ GlobalHealthRisks_report_full.pdf. (accessed 10 January 2010).

4 Hofsø D, Ueland T, Hager H, Jenssen T, Bollerslev J, Godang K, Aukrust P, Røislien J \& Hjelmesæth J. Inflammatory mediators in morbidly obese subjects: associations with glucose abnormalities and changes after oral glucose. European Journal of Endocrinology 2009161 451-458. (doi:10.1530/EJE-09-0421)

5 Katzmarzyk PT, Church TS, Janssen I, Ross R \& Blair SN. Metabolic syndrome, obesity, and mortality: impact of cardiorespiratory fitness. Diabetes Care 200528 391-397. (doi:10.2337/diacare. 28.2.391)

6 Lauer MS, Anderson KM, Kannel WB \& Levy D. The impact of obesity on left ventricular mass and geometry. The Framingham Heart Study. Journal of the American Medical Association 1991266 231-236. (doi:10.1001/jama.266.2.231)

7 Metcalf P, Baker J, Scott A, Wild C, Scragg R \& Dryson E. Albuminuria in people at least 40 years old: effect of obesity, hypertension, and hyperlipidemia. Clinical Chemistry $19923 \mathbf{3 8}$ 1802-1808.

8 Sturm R. Increases in morbid obesity in the USA: 2000-2005. Public Health 2007121 492-496. (doi:10.1016/j.puhe.2007.01.006) 
9 Buchwald H \& Oien DM. Metabolic/bariatric surgery worldwide 2008. Obesity Surgery 200919 1605-1611. (doi:10.1007/ s11695-009-0014-5)

10 Sjöström L, Lindroos AK, Peltonen M, Torgerson J, Bouchard C, Carlsson B, Dahlgren S, Larsson B, Narbro K, Sjöström CD, Sullivan M, Wedel H \& Swedish Obese Subjects Study Scientific Group. Lifestyle, diabetes, and cardiovascular risk factors 10 years after bariatric surgery. New England Journal of Medicine 2004351 2683-2693. (doi:10.1056/NEJMoa035622)

11 Dixon JB, O’Brien PE, Playfair J, Chapman L, Schachter LM, Skinner S, Proietto J, Bailey M \& Anderson M. Adjustable gastric banding and conventional therapy for type 2 diabetes: a randomized controlled trial. Journal of the American Medical Association 2008299 316-323. (doi:10.1001/jama.299.3.316)

12 Karason K, Wallentin I, Larsson B \& Sjöström L. Effects of obesity and weight loss on left ventricular mass and relative wall thickness: survey and intervention study. BMJ $1997 \quad 315$ 912-916.

13 Navarro-Díaz M, Serra A, Romero R, Bonet J, Bayés B, Homs M, Pérez N \& Bonal J. Effect of drastic weight loss after bariatric surgery on renal parameters in extremely obese patients: longterm follow-up. Journal of the American Society of Nephrology 2006 17 213S-217S. (doi:10.1681/ASN.2006080917)

14 Sugerman HJ, Wolfe LG, Sica DA \& Clore JN. Diabetes and hypertension in severe obesity and effects of gastric bypassinduced weight loss. Annals of Surgery 2003237 751-756. (doi:10.1097/00000658-200306000-00002)

15 Pories WJ, MacDonald KG Jr, Morgan EJ, Sinha MK, Dohm GL, Swanson MS, Barakat HA, Khazanie PG, Leggett-Frazier N, Long SD, O'Brian KF \& Caro JF. Surgical treatment of obesity and its effect on diabetes: 10-y follow-up. American Journal of Clinical Nutrition $1992 \mathbf{5 5}$ 582S-585S.

16 Esposito K, Pontillo A, Di Palo C, Giugliano G, Masella M, Marfella R \& Giugliano D. Effect of weight loss and lifestyle changes on vascular inflammatory markers in obese women: a randomized trial. Journal of the American Medical Association 2003289 1799-1804. (doi:10.1001/jama.289.14.1799)

17 Look AHEAD Research Group, Pi-Sunyer X, Blackburn G, Brancati FL, Bray GA, Bright R, Clark JM, Curtis JM, Espeland MA, Foreyt JP, Graves K, Haffner SM, Harrison B, Hill JO, Horton ES, Jakicic J, Jeffery RW, Johnson KC, Kahn S, Kelley DE, Kitabchi AE, Knowler WC, Lewis CE, Maschak-Carey BJ, Montgomery B, Nathan DM, Patricio J, Peters A, Redmon JB, Reeves RS, Ryan DH, Safford M, VanDorsten B, Wadden TA, Wagenknecht L, Wesche-Thobaben J, Wing RR \& Yanovski SZ. Reduction in weight and cardiovascular disease risk factors in individuals with type 2 diabetes: one-year results of the Look AHEAD trial. Diabetes Care 200730 1374-1383. (doi:10.2337/ dc07-0048)

18 Ratner R, Goldberg R, Haffner S, Marcovina S, Orchard T, Fowler S, Temprosa M \& Diabetes Prevention Program Research Group. Impact of intensive lifestyle and metformin therapy on cardiovascular disease risk factors in the diabetes prevention program. Diabetes Care 200528 888-894. (doi:10.2337/diacare. 28.4.888)

19 Ryan DH, Johnson WD, Myers VH, Prather TL, McGlone MM, Rood J, Brantley PJ, Bray GA, Gupta AK, Broussard AP, Barootes BG, Elkins BL, Gaudin DE, Savory RL, Brock RD, Datz G, Pothakamuri SR, McKnight GT, Stenlof K \& Sjöström LV. Nonsurgical weight loss for extreme obesity in primary care settings: results of the Louisiana Obese Subjects Study. Archives of Internal Medicine $2010 \mathbf{1 7 0} 146-154$. (doi:10.1001/archinternmed.2009.508)

20 Eriksson J, Taimela S \& Koivisto VA. Exercise and the metabolic syndrome. Diabetologia $1997 \quad 40 \quad 125-135$. (doi:10.1007/ s001250050653)

21 Norwegian Directorate of Health. Forebygging og behandling av overvekt/fedme i helsetjenesten (in Norwegian). Available from: http://www.helsedirektoratet.no/vp/multimedia/archive/00001/ IS-1150_1075a.pdf. (accessed 10 January 2010).
22 Buchwald H. Consensus Conference. Bariatric surgery for morbid obesity: health implications for patients, health professionals, and third-party payers. Journal of the American College of Surgeons 2005200 593-604. (doi:10.1016/j.jamcollsurg.2004. 10.039)

23 Aasheim ET, Björkman S, Søvik TT, Engström M, Hanvold SE, Mala T, Olbers T \& Bøhmer T. Vitamin status after bariatric surgery: a randomized study of gastric bypass and duodenal switch. American Journal of Clinical Nutrition 200990 15-22. (doi:10.3945/ajcn.2009.27583)

24 Ministry of Health and Care Services. Recipe for a healthier diet. Norwegian Action Plan on Nutrition (2007-2011). Available from: http://www.regjeringen.no/upload/HOD/Dokumenter $\% 20$ FHA/SEM/Kostholdsplanen/IS-0238\%20kortversjon\%20eng.pdf (accessed 10 January 2010).

25 American Diabetes Association. Diagnosis and classification of diabetes mellitus. Diabetes Care 200831 55S-60S. (doi:10.2337/ dc08-S055)

26 Buse JB, Caprio S, Cefalu WT, Ceriello A, Del Prato S, Inzucchi SE, McLaughlin S, Phillips GL II, Robertson RP, Rubino F, Kahn R \& Kirkman MS. How do we define cure of diabetes? Diabetes Care 200932 2133-2135. (doi:10.2337/dc09-9036)

27 Chobanian AV, Bakris GL, Black HR, Cushman WC, Green LA, Izzo JL Jr, Jones DW, Materson BJ, Oparil S, Wright JT Jr, Roccella EJ \& Joint National Committee on Prevention, Detection, Evaluation and Treatment of High Blood Pressure. National Heart, Lung, and Blood Institute: National High Blood Pressure Education Program Coordinating Committee. Seventh report of the Joint National Committee on Prevention, Detection, Evaluation, and Treatment of High Blood Pressure. Hypertension 200342 1206-1252. (doi:10.1161/01.HYP.0000107251.49515.c2)

28 Grundy SM, Cleeman JI, Daniels SR, Donato KA, Eckel RH, Franklin BA, Gordon DJ, Krauss RM, Savage PJ, Smith SC Jr, Spertus JA, Costa F \& American Heart Association; National Heart, Lung, and Blood Institute. Diagnosis and management of the metabolic syndrome: an American Heart Association/ National Heart, Lung, and Blood Institute Scientific Statement. Circulation 2005112 2735-2752. (doi:10.1161/CIRCULATIONAHA.105.169404)

29 de Jong PE \& Curhan GC. Screening, monitoring, and treatment of albuminuria: public health perspectives. Journal of the American Society of Nephrology 200617 2120-2126. (doi:10.1681/ASN. 2006010097)

30 Dahlöf B, Devereux RB, Julius S, Kjeldsen SE, Beevers G, de Faire U, Fyhrquist F, Hedner T, Ibsen H, Kristianson K, LederballePedersen O, Lindholm LH, Nieminen MS, Omvik P, Oparil S \& Wedel H. Characteristics of 9194 patients with left ventricular hypertrophy: the LIFE study. Losartan Intervention For Endpoint Reduction in Hypertension. Hypertension 199832 989-997.

31 Okin PM, Devereux RB, Liu JE, Oikarinen L, Jern S, Kjeldsen SE, Julius S, Wachtell K, Nieminen MS \& Dahlöf B. Regression of electrocardiographic left ventricular hypertrophy predicts regression of echocardiographic left ventricular mass: the LIFE study. Journal of Human Hypertension 200418 403-409. (doi:10. 1038/sj.jhh.1001707)

32 Andersen LF, Solvoll K, Johansson LR, Salminen I, Aro A \& Drevon CA. Evaluation of a food frequency questionnaire with weighed records, fatty acids, and $\alpha$-tocopherol in adipose tissue and serum. American Journal of Epidemiology 1999150 75-87.

33 Haskell WL, Lee IM, Pate RR, Powell KE, Blair SN, Franklin BA, Macera CA, Heath GW, Thompson PD, Bauman A \& American College of Sports Medicine; American Heart Association. Physical activity and public health: updated recommendation for adults from the American College of Sports Medicine and the American Heart Association. Circulation 2007116 1081-1093. (doi:10. 1161/CIRCULATIONAHA.107.185649)

34 Palardy J. Havrankova J, Lepage R, Matte R, Bélanger R, D'Amour P \& Ste-Marie LG. Blood glucose measurements during symptomatic episodes in patients with suspected postprandial hypoglycemia. New England Journal of Medicine 1989321 1421-1425. (doi:10. 1056/NEJM198911233212101) 
35 The DECODE Study Group. Glucose tolerance and mortality: comparison of WHO and American Diabetes Association diagnostic criteria. Lancet $1999354617-621$. (doi:10.1016/S01406736(98)12131-1)

36 Lewington S, Clarke R, Qizilbash N, Peto R \& Collins R. Age-specific relevance of usual blood pressure to vascular mortality: a metaanalysis of individual data for one million adults in 61 prospective studies. Lancet 2002360 1903-1913. (doi:10.1016/SO1406736(02)11911-8)

37 Service GJ, Thompson GB, Service FJ, Andrews JC, CollazoClavell ML \& Lloyd RV. Hyperinsulinemic hypoglycemia with nesidioblastosis after gastric-bypass surgery. New England Journal of Medicine 2005353 249-254. (doi:10.1056/NEJMoa 043690)

38 Bonds DE, Miller ME, Bergenstal RM, Buse JB, Byington RP, Cutler JA, Dudl RJ, Ismail-Beigi F, Kimel AR, Hoogwerf B, Horowitz KR, Savage PJ, Seaquist ER, Simmons DL, Sivitz WI, Speril-Hillen JM \& Sweeney ME. The association between symptomatic, severe hypoglycaemia and mortality in type 2 diabetes: retrospective epidemiological analysis of the ACCORD study. BMJ 2010340 b4909. (doi:10.1136/bmj.b4909)

39 Diabetes Prevention Program Research Group. Changes in albumin excretion in the diabetes prevention program. Diabetes Care 200932 720-725. (doi:10.2337/dc08-1400)

40 Longitudinal Assessment of Bariatric Surgery (LABS) Consortium , Flum DR, Belle SH, King WC, Wahed AS, Berk P, Chapman W, Pories W, Courcoulas A, McCloskey C, Mitchell J, Patterson E, Pomp A, Staten MA, Yanovski SZ, Thirlby R \& Wolfe B. Perioperative safety in the longitudinal assessment of bariatric surgery. New England Journal of Medicine 2009361 445-454. (doi:10.1056/NEJMoa0901836)
41 Gasteyger C, Suter M, Gaillard RC \& Giusti V. Nutritional deficiencies after Roux-en-Y gastric bypass for morbid obesity often cannot be prevented by standard multivitamin supplementation. American Journal of Clinical Nutrition $2008 \mathbf{8 7}$ $1128-1133$.

42 Sjöström L, Narbro K, Sjöström CD, Karason K, Larsson B, Wedel H, Lystig T, Sullivan M, Bouchard C, Carlsson B, Bengtsson C, Dahlgren S, Gummesson A, Jacobson P, Karlsson J, Lindroos AK, Lönroth $H$, Näslund I, Olbers T, Stenlöf K, Torgerson J, Agren G, Carlsson LM \& Swedish Obese Subjects Study. Effects of bariatric surgery on mortality in Swedish obese subjects. New England Journal of Medicine 2007357 741-752. (doi:10.1056/NEJMoa066254)

43 Anderson JW, Conley SB \& Nicholas AS. One hundred pound weight losses with an intensive behavioral program: changes in risk factors in 118 patients with long-term follow-up. American Journal of Clinical Nutrition 200786 301-307.

44 Blair SN, Kohl HW III, Barlow CE, Paffenbarger RS Jr, Gibbons LW \& Macera CA. Changes in physical fitness and all-cause mortality. A prospective study of healthy and unhealthy men. Journal of the American Medical Association 1995273 1093-1098. (doi:10. 1001/jama.273.14.1093)

45 Papalazarou A, Yannakoulia M, Kavouras SA, Komesidou V, Dimitriadis G, Papakonstantinou A \& Sidossis LS. Lifestyle intervention favorably affects weight loss and maintenance following obesity surgery. Obesity 201018 1348-1353. (doi:10. 1038/oby.2009.346)

Received 12 August 2010

Accepted 26 August 2010 